\title{
Laparoscopic Cholecystectomy in the elderly
}

\author{
S Spiezia*, S Grassia, D De Rosa, DG Palmieri, N Carlomagno, C Dodaro, A Renda \\ From XXIII Annual Meeting of the Italian Society of Geriatric Surgery \\ Lecce, Italy. 2-4 December 2010
}

\section{Background}

Laparoscopic cholecystectomy (LC) has shown benefits, in order to become the universal gold standard for cholelithiasis and other diseases of the gallbladder. Such pathologies are very common in the elderly, but in these cases LC might pose problems because of the comorbidity frequently associated. The aim of this study is to evaluate the outcome of LC in the elderly.

\section{Materials and methods}

A retrospective study was conducted on 204 patients affected by symptomatic cholelithiasis and other diseases of the gallbladder observed during the last four years (from January 2006 to December 2009). Patients were divided into two groups according to their age :a) $<75$ y. o. - b) $>=75$ y. o., to compare operative time, conversion rate to open cholecystectomy, complication rate and length of stay. Other parameters were evaluated such as sex, comorbidity (cardiovascular and respiratory diseases, hypertension, diabetes), previous abdominal surgery, diagnosis of acute cholecystitis and lithiasis of the common bile duct, biochemistry (leukocytosis, hyperbilirubinemia, transaminase) and ultrasonography.

\section{Results}

There were 144 patients aged $<75$ y. o. (Group a) and 60 patients $>75 \mathrm{y}$. o. (Group b). The majority of the patients in each group were female (90 in Group a and 40 in group b). 184 patients underwent LC and the remaining 20 underwent open surgery. Comorbidity was higher in the elderly patients ( $40 \%$ vs $22 \%$ ).

Open cholecystectomies were more frequently performed in the elderly (13.33\% vs $8.3 \%$ ) because of previous surgery, cardiac and/or respiratory failure and gangrenous cholecystis. Scleroatrophy and acute
Table 1

\begin{tabular}{lll}
\hline & Group a & Group b \\
\hline Conversion rate & $2.27 \%$ & $1.92 \%$ \\
Complication rate & $3 \%$ & $3.85 \%$ \\
Operative time & $45 \mathrm{~min}$ & $50 \mathrm{~min}$ \\
Hospital stay & 3.5 days & 4 days \\
\hline
\end{tabular}

inflammation were the main causes of conversion and had a marginal independent effect on the development of complications among elderly patients. After open cholecystectomy there were no complications but the hospital stay was longer Table 1.

\section{Conclusion}

LC is the gold-standard for the elderly too. Results are quite similar in both groups thanks to an accurate selection of cases.

Published: 24 August 2011

\section{References}

1. Bingener J, Richards M, Schwesinger W, et al: Laparoscopic Cholecystectomy for Elderly Patients. Arch Surg 2003, 138:531-536.

2. Polychronidis A, Botaitis S, Tsaroucha A: Laparoscopic Cholecystectomy in Elderly Patients. J Gastrointestin Liver Dis 2008, 17:309-313.

3. Borzellino G, De Manzoni G, Ricci F, et al: Emergency cholecystotomy and subsequent cholecystectomy for acute gallstone in the elderly. Br I Surg 1999, 86:1521-1525.

4. Pessaux P, Tuech JJ, Derouet N, et al: Laparoscopic cholecystectomy in the elderly: a prospective study. Surg Endosc 2000, 14:1067-1069.

5. Kauvar DS, Brown BD, Braswell AW, et al: Laparoscopic cholecystectomy in the elderly: increased operative complications and conversions to laparotomy. J Laparoendosc Adv Surg Tech A 2005, 15(4):379-382.

doi:10.1186/1471-2318-11-S1-A59

Cite this article as: Spiezia et al:: Laparoscopic Cholecystectomy in the elderly. BMC Geriatrics 2011 11(Suppl 1):A59.

\footnotetext{
* Correspondence: sergiospezia@libero.it

University Department of Surgical, Anesthesiology-Reanimation and

Emergency Sciences. University of Naples "Federico II", Italy
} 